\title{
A CLINICAL STUDY OF NEUROLOGICAL COMPLICATIONS IN PREGNANCY AND UPTO 6 WEEKS POSTPARTUM
}

\author{
Anil Kumar Thatikondaㄹ, Tirumal Rao Balasankula², Abhilash Thatikala³, Sree Rangalakshmi Gudivella ${ }^{4}$, Ramesh Ramchandram ${ }^{5}$, \\ Archana Bethala 6
}

${ }^{1}$ Assistant Professor, Department of Neurology, Osmania Medical College, Hyderabad, Telangana, India. 2Postgraduate Student, Department of Neurology, Osmania Medical College, Hyderabad, Telangana, India. 3Postgraduate Student, Department of Neurology, Osmania Medical College, Hyderabad, Telangana, India. ${ }^{4}$ Professor and HOD, Department of Neurology, Osmania Medical College, Hyderabad, Telangana, India. ${ }^{5}$ Associate Professor, Department of Neurology, Osmania Medical College, Hyderabad, Telangana, India. ${ }^{6}$ Assistant Professor, Department of Neurology, Osmania Medical College, Hyderabad, Telangana, India.

\section{BACKGROUND}

ABSTRACT

Pregnancy is associated with major hormonal changes and other physiological changes. Several neurological conditions may appear during pregnancy that are either unique to or occur with increased frequency during pregnancy and puerperium. Preexisting disorders such as epilepsy may worsen in one-third of pregnant patients and seizures are common during peripartum period. Changes in haemodynamics, blood volume and hormonal effects on the vessel wall increase risk of cerebrovascular disorders during pregnancy and the postpartum period. Cerebral venous sinus thrombosis is common in the postpartum period. Brain tumours may enlarge during pregnancy because of fluid retention and the presence of oestrogen and progesterone receptors on the tumour cells. Neurological disorders may influence the management of obstetric outcomes. In this study, the common neurological problems during pregnancy and six weeks of postpartum period are discussed.

Aim- To study the neurological disorders and clinical features occurring during pregnancy and 6 weeks of postpartum.

\section{MATERIALS AND METHODS}

This was a descriptive study carried out in Osmania, Hyderabad (December 2015 - January 2018).

Source of Data: All the pregnant women attending OP and admitted as inpatients in Osmania General Hospital. Total 67 patients attending Outpatient Department of Neurology and admitted in the hospital with neurological disorders were included. Patients with neurological disorders due to trauma, infections and obstetrical procedures were excluded from the study. A total of 67 patients were included in the study and consent was taken from them. Demographic data and data of history and detailed examination were collected. Basic and relevant investigations were done including Brain Imaging, CSF analysis, EEG, NCS, 2D Echocardiography and ANA profile whenever necessary.

\section{RESULTS}

Most patients were in the age group of 21 - 25 years (61\%). Age of patients ranged between 19 - 35. Most patients presented in postpartum period (41\%). Seizures (46\%) was the most common presentation followed by stroke (36\%). Most of the patients $(45 \%)$ with seizures were in $2^{\text {nd }}$ trimester. $87.5 \%$ patients with stroke presented in postpartum period. 3 patients had facial palsy. 2 patients presented with astrocytomas and 3 patients had chorea.

\section{CONCLUSION}

Many neurological disorders are encountered in pregnancy. In our study, we have identified 7 different conditions, of which seizures was the most common presentation. Effect of the condition and its treatment on pregnancy and vice versa should always be kept in mind. Appropriate management with collaborative effort of obstetricians, neurologists, neurosurgeons and paediatricians at specialised centres should be undertaken for successful maternal and foetal outcomes.

\section{KEY WORDS}

Pregnancy, Postpartum, Stroke, Seizures.

HOW TO CITE THIS ARTICLE: Thatikonda AK, Balasankula TR, Thatikala A, et al. A clinical study of neurological complications in pregnancy and upto 6 weeks postpartum. J. Evolution Med. Dent. Sci. 2018;7(38):4161-4166, DOI: 10.14260/jemds/2018/931

'Financial or Other Competing Interest': None.

Submission 26-06-2018, Peer Review 31-08-2018,

Acceptance 07-09-2018, Published 17-09-2018.

Corresponding Author:

Dr. Anil Kumar Thatikonda,

Assistant Professor,

Department of Neurology,

$2^{\text {nd }}$ Floor, QQDC Building,

Osmania General Hospital, Afzalgunz,

Hyderabad-500012, Telangana, India.

E-mail: anildr8888@gmail.com

DOI: $10.14260 /$ jemds $/ 2018 / 931$

(c) (i) $\ominus$

\section{BACKGROUND}

Several neurological conditions may appear during pregnancy, that are either unique to or occur with increased frequency during pregnancy and puerperium. Pre-existing disorders such as epilepsy may worsen in one-third of pregnant patients and seizures are common during peripartum period. Changes in haemodynamics, blood volume and hormonal effects on the vessel wall increase the risk of cerebrovascular disorders during pregnancy and the postpartum period. Cerebral venous sinus thrombosis is common in the postpartum period. Brain tumours may enlarge during pregnancy because of fluid retention and the presence of oestrogen and progesterone receptors on the 
tumour cells. Neurological disorders may influence the management of obstetric outcomes. In this study, the common neurological problems during pregnancy and six weeks of postpartum period are discussed.

\section{Aims and Objectives of the Study}

To study the neurological disorders and clinical features occurring during pregnancy and 6 weeks of postpartum.

\section{MATERIALS AND METHODS}

This was a descriptive study carried out in Osmania General Hospital OPD/IPD with neurological symptoms, Hyderabad (December 2015 - January 2018). 67 patients were included in the study and consent was taken from them. All the pregnant women attending OP and admitted as inpatients in Osmania General Hospital were included in this study. Neurological disorders due to trauma, infections and obstetrical procedure were excluded from this study. Age, duration of pregnancy and history were noted. Detailed neurological examination was done. Basic and relevant investigations were done including brain and spine imaging, CSF analysis, EEG, NCS, 2D echo and ANA profile whenever necessary. MS Excel 2010 was used for descriptive statistics.

\section{Inclusion Criteria}

Sixty seven pregnancy patients and postpartum 6 weeks of post-delivery with neurological symptom patients who met with inclusion criteria and were included in the study.

\section{RESULTS}

Most patients belonged to age between 21 - 25 years (62\%) as shown in Figure 1.

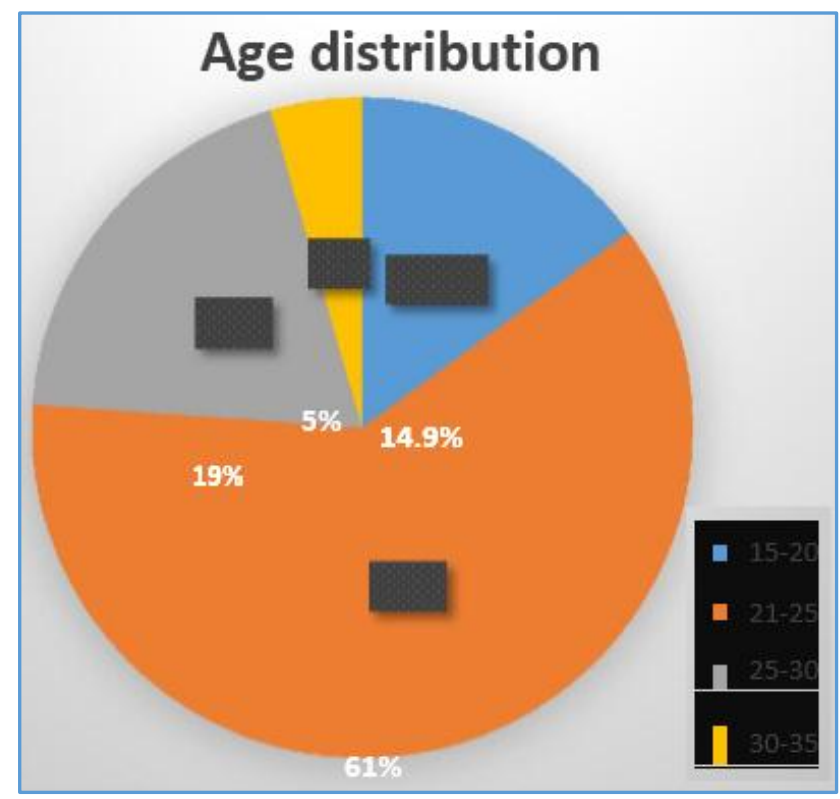

Figure 1. Age Distribution
Most of the patients were in postpartum period (41\%) followed by second trimester (32\%) as shown in Figure 2.

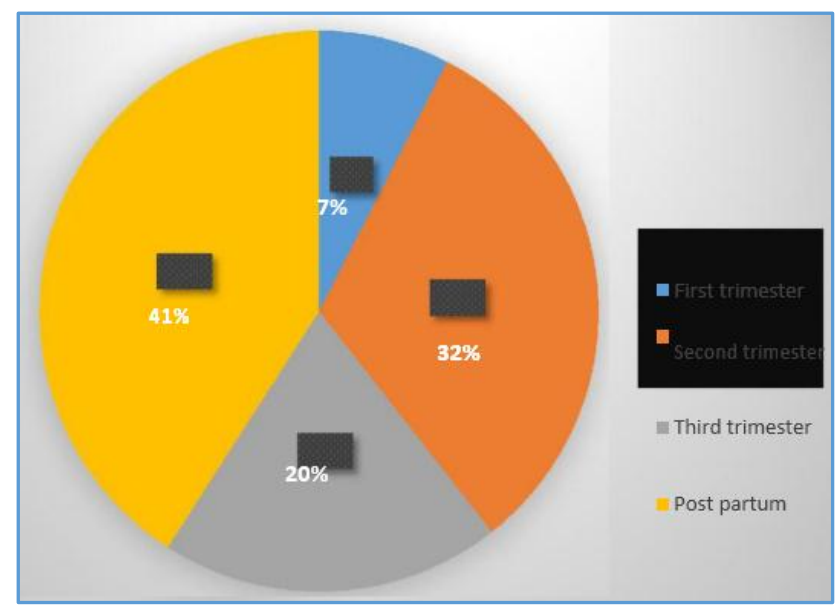

Figure 2. Distribution according to Pregnancy Status

Out of total sixty seven cases, seizures were found to be the most common presentation followed by cerebrovascular disorders. Other patients presented with facial nerve palsy, chorea and GBS as shown in Table 1.

\begin{tabular}{|c|c|}
\hline Generalised tonic-clonic seizures & $31(46.2 \%)$ \\
\hline Cerebrovascular disorders & $24(35.8 \%)$ \\
\hline Peripheral neuropathy & $3(4.4 \%)$ \\
\hline Tumours & $3(4.4 \%)$ \\
\hline Facial nerve palsy & $3(4.4 \%)$ \\
\hline Movement disorder & $3(4.4 \%)$ \\
\hline Table 1. Neurological Disorders during Pregnancy \\
\hline
\end{tabular}

Most patients with seizures were in second (45\%) and third trimesters (35\%) as shown in Table 2.

\begin{tabular}{|c|c|c|}
\hline Stage of Pregnancy & Number & Percentage \\
\hline First trimester & 3 & 9.6 \\
\hline Second trimester & 14 & 45.16 \\
\hline Third trimester & 11 & 35.4 \\
\hline Postpartum & 3 & 9.6 \\
\hline
\end{tabular}

24 patients presented with cerebrovascular disorders, out of which PRES was the most common as shown in Figure 3.

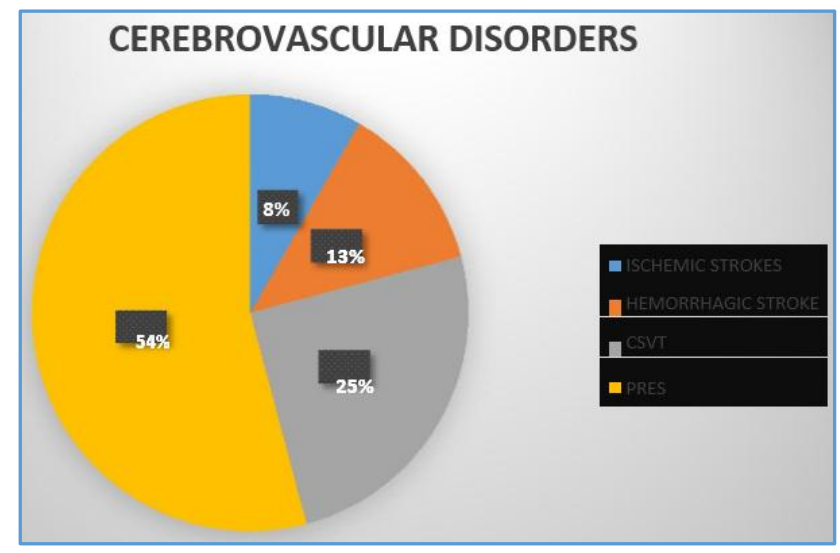

Figure 3. Types of Cerebrovascular Accidents 
Most of the cerebrovascular disorder events occurred during the postpartum period as shown in Table 3.

\begin{tabular}{|c|c|c|}
\hline Stage of Pregnancy & Number & Percentage \\
\hline First trimester & 0 & 0 \\
\hline Second trimester & 1 & 4.16 \\
\hline Third trimester & 2 & 8.3 \\
\hline Postpartum & 21 & 87.5 \\
\hline
\end{tabular}

Three patients presented with chorea. No aetiology was found in two cases. One had Wilson's disease. Two had presented during the first trimester and the other in the second trimester. Three patients had presented with facial nerve palsy. One patient had bilateral facial nerve palsy during postpartum period. Other two patients had presented during $2^{\text {nd }}$ trimester with unilateral facial nerve palsy. Three patients had presented with GBS. One patient had presented during second trimester. Other two patients had presented during postpartum period. One case who presented with raised intracranial pressure symptoms during $2^{\text {nd }}$ trimester was found to have Glioblastoma. Another case of primi presenting during postpartum period with facial nerve palsy was found to have glioma. One patient had Neurofibroma.

\section{DISCUSSION}

A wide range of neurologic conditions can affect women during pregnancy and puerperium. The primary neurological disorders studied in relation to pregnancy include eclampsia, strokes, epilepsy, benign intracranial hypertension, CNS tumours, Bell's palsy, obstetric pressure palsies, demyelinating diseases of the central/ peripheral nervous system and neuromuscular junction disorders (Myasthenia gravis). Neurological diseases may be incidental to pregnancy (e.g. meningitis). Patients may also present with secondary neurological disorders such as metabolic encephalopathies secondary to hypoxia-ischaemia, hypoglycaemia, hepatic failure, azotaemia, hypercalcaemia and nervous system disorders secondary to nutritional deficiencies and endocrine dysfunction.

Sixty seven cases presented to our hospital with various neurological disorders. Out of 67 thirty one cases of generalised seizures, eleven cases of cerebrovascular disorders, in that three ischaemic, two haemorrhagic and six cases of CSVT, three cases each of neoplasms, peripheral neuropathy and movement disorders were reported. Among three cases of neoplasm one was glioma, one was glioblastoma and the other presented with neurofibromatosis. All cases of peripheral neuropathy were GBS. Among three cases of movement disorders, all presented with chorea. Two were diagnosed as chorea gravidarum and one was diagnosed to be Wilson's disease.

\begin{tabular}{|c|c|c|c|c|c|c|c|}
\hline Condition & To et al ${ }^{1}$ & Gupta et al ${ }^{2}$ & Janaki et al $^{3}$ & Srinivasan et al ${ }^{4}$ & Agarval et al5 & Shubha et al ${ }^{6}$ & Present Study \\
\hline Total No. & 161 & 76 & 97 & 68 & 87 & 52 & 67 \\
\hline Epilepsy & $\begin{array}{c}102 \\
(63.3 \%)\end{array}$ & $\begin{array}{c}22 \\
(28.9 \%)\end{array}$ & $\begin{array}{c}30 \\
(30.9 \%)\end{array}$ & $\begin{array}{c}17 \\
(23.5 \%)\end{array}$ & $\begin{array}{c}5 \\
(6.7 \%)\end{array}$ & $\begin{array}{c}23 \\
(44.2 \%)\end{array}$ & $\begin{array}{c}31 \\
(46.2 \%)\end{array}$ \\
\hline $\begin{array}{c}\text { Cerebrovascular } \\
\text { diseases }\end{array}$ & $\begin{array}{c}7 \\
(4.9 \%)\end{array}$ & $\begin{array}{c}9 \\
(11.9 \%)\end{array}$ & $\begin{array}{c}48 \\
(49.5 \%)\end{array}$ & $\begin{array}{c}41 \\
(60.3 \%)\end{array}$ & $\begin{array}{c}72 \\
(82.7 \%)\end{array}$ & $\begin{array}{c}2 \\
(3.8 \%)\end{array}$ & $\begin{array}{c}24 \\
(35.8 \%)\end{array}$ \\
\hline CNS tumours & $\begin{array}{c}12 \\
(7.5 \%) \\
\end{array}$ & $\begin{array}{c}1 \\
(1.3 \%)\end{array}$ & $\begin{array}{c}7 \\
(7.2 \%)\end{array}$ & $\begin{array}{c}16 \\
(23.5 \%)\end{array}$ & $\begin{array}{c}16 \\
(18 \%)\end{array}$ & $\begin{array}{c}2 \\
(3.8 \%)\end{array}$ & $\begin{array}{c}3 \\
(4.4 \%)\end{array}$ \\
\hline Neuropathies & $\begin{array}{c}12 \\
(7.5 \%)\end{array}$ & $\begin{array}{c}1 \\
(1.3 \%)\end{array}$ & 1 & $\begin{array}{c}1 \\
(1.5 \%)\end{array}$ & $\begin{array}{c}2 \\
(2.3 \%)\end{array}$ & $\begin{array}{c}5 \\
(9.6 \%)\end{array}$ & $\begin{array}{c}3 \\
(4.4 \%)\end{array}$ \\
\hline $\begin{array}{l}\text { Movement } \\
\text { disorder }\end{array}$ & - & - & - & - & - & $\begin{array}{c}2 \\
(3.8 \%)\end{array}$ & $\begin{array}{c}3 \\
(4.4 \%)\end{array}$ \\
\hline Facial palsy & - & - & - & - & - & - & $3(4.4 \%)$ \\
\hline
\end{tabular}

This Table 4 shows comparative analysis of different neurological illnesses in pregnancy and puerperium across various studies. Epilepsy was found to be major neurological ailment varying between $23-63 \%$, except one study conducted by Agarwal et $\mathrm{al}^{5}$ which showed higher incidence of cerebrovascular disease. The other disorders like CNS tumours, cranial nerve palsies, neuropathies and movement disorders constitute lesser proportion of cases and distribution is also variable.

There are a number of factors that can affect seizure frequency in women with epilepsy who are pregnant. The major factors are hormonal changes that accompany the pregnant state, changes in behaviour and changes in metabolism that alter the concentrations of antiepileptic drugs. One-third of women with epilepsy will have an increase in seizure frequency during pregnancy. Ten to twenty percent will have a decrease in seizure frequency. A small number of women will have one or two seizures during pregnancy and never have them at any other time in their life. ${ }^{7}$ Majority of the women with epilepsy will not have their seizure frequency altered. Studies show that changes in seizure frequency do not depend on the seizure type, age of the mother, duration of epilepsy or the number of seizures that occurred in a previous pregnancy. In general, it is believed that most seizures will occur toward the end of the pregnancy; however, one-third of seizures can occur in the first trimester. A small percentage of women will have a permanent increase in their seizure frequency following pregnancy. A recent evaluation of previous studies found no clear evidence to state if seizures were increased or decreased in general in pregnant women with epilepsy.

In the current study, seizure disorder was the most common cause of neurological referral of a pregnant patient in our institute. There is a wide range of variability of incidence of seizure in pregnancy in various studies conducted in India. ${ }^{1-6}$

This variation may be attributed to the facilities available at the centre for neurological care or number of cases referred from a gynaecological centre. 
In our study, patients aged between 21 - 25 years of age had higher incidence of seizure disorder.

\begin{tabular}{|c|c|c|c|c|}
\hline Trimester & $\begin{array}{c}\text { Gupta } \\
\text { et al }\end{array}$ & $\begin{array}{c}\text { Sarella LK } \\
\text { et al8 }^{\mathbf{8}}\end{array}$ & Shubha L6 $^{\mathbf{6}}$ & $\begin{array}{c}\text { Present } \\
\text { Study }\end{array}$ \\
\hline $1^{\text {st }}$ Trimester & $5(22.72 \%)$ & $4(14.81 \%)$ & $6(27.27 \%)$ & $03(9.6 \%)$ \\
\hline $2^{\text {nd }}$ Trimester & $6(27.27 \%)$ & $6(22.22 \%)$ & $5(22.7 \%)$ & $13(41 \%)$ \\
\hline $3^{\text {rd }}$ Trimester & $5(22.72 \%)$ & $13(48.14 \%)$ & $8(36.36 \%)$ & $11(35.4 \%)$ \\
\hline Postpartum & $6(27.27 \%)$ & $4(14.81 \%)$ & $4(17.4 \%)$ & $4(12.9 \%)$ \\
\hline \multicolumn{3}{|c|}{ Table 5. Trimester Wise Incidence of Seizure Disorder } \\
\hline
\end{tabular}

In our study most of the patients with seizures were in second trimester (41\%) followed by patients in third trimester (35.4\%), which is in contrast to previously published studies that showed a higher incidence of seizures in the third trimester as depicted in Table $5.6,8 \mathrm{In}$ a study by Gupta et $\mathrm{al}^{2}{ }^{2}$ there was higher incidence of seizures in second trimester and postpartum. Most seizures occur towards the end of the pregnancy; however, one-third of seizures can occur in the first trimester. ${ }^{9}$ In the current study, 38.7\% had new-onset seizure during pregnancy. Rest of the patients had prior history of seizure disorder, of which $32.2 \%$ were already on AEDs and had seizures despite being compliant with therapy. These results were in accordance with study conducted by Gupta et al. ${ }^{2}$

There were limited studies available to evaluate incidence of cerebrovascular disorders in pregnancy and there is wide variability in the data available. In three population based studies, the incidence of all types of stroke ranged from four-to-seven cases per 100,000 pregnancies. However, data from the National Inpatient Sample of the Healthcare Cost and Utilisation Project suggest that the incidence of pregnancy associated stroke has risen since the 1990s. These data estimate the incidence of all types of pregnancy associated stroke to be 25 to 34 per 100,000 deliveries. Table 6 depicts the incidence of stroke in pregnancy in various studies.

\begin{tabular}{|c|c|c|c|}
\hline \multirow{2}{*}{ Study } & \multirow{2}{*}{ Location } & \multicolumn{2}{|c|}{ Ischaemic Haemorrhagic } \\
\hline & & Stroke & Stroke \\
\hline Feske et al 10 & Boston & 17 & 36 \\
\hline Laing et al11 & Taiwan & 11 & 21 \\
\hline Jeng et al ${ }^{12}$ & Taiwan & 27 & 22 \\
\hline Jaigobein et al ${ }^{13}$ & Toronto & 21 & 13 \\
\hline Witllin et al ${ }^{14}$ & $\begin{array}{c}\text { Memphis } \\
\text { Hospital }\end{array}$ & 14 & 06 \\
\hline Kittner et al ${ }^{15}$ & Washington DC & 17 & 14 \\
\hline Sharshar et al 16 & France & 15 & 16 \\
\hline Awada et al ${ }^{17}$ & Saudi Arabia & 09 & 03 \\
\hline Present study & $\begin{array}{c}\text { Osmania } \\
\text { General } \\
\text { Hospital }\end{array}$ & 02 & 03 \\
\hline le 6. & $\begin{array}{l}\text { dence of Hae } \\
\text { Strokes in } \mathrm{P}\end{array}$ & $\begin{array}{l}\text { rrhagi } \\
\text { nancy }\end{array}$ & chaemic \\
\hline
\end{tabular}

In the present study $35.8 \%$ patients presented with cerebrovascular disorders, of which $12.5 \%$ were ischaemic stroke, $8.3 \%$ were haemorrhagic stroke, $25 \%$ had CSVT and $54.1 \%$ had PRES.

Postpartum angiopathy is one of several conditions included in the spectrum of the Reversible Cerebral Vasoconstriction Syndromes (RCVS).18 Postpartum angiopathy is characterised by severe headaches and reversible narrowing of intracerebral arteries, often complicated by seizures, reversible brain oedema, lobar haemorrhage, convexity (non-aneurysmal) subarachnoid haemorrhage and ischaemic strokes. Postpartum angiopathy is a non-inflammatory, vasoconstrictive condition. Approximately, one-third of patients with postpartum angiopathy are noted to have reversible cerebral oedema and clinical features (Headaches, Seizures), which are very similar to patients with PRES and more than half the patients with PRES show evidence of cerebral artery narrowing on vascular imaging. Hence, postpartum angiopathy and PRES are considered overlapping conditions. In our study, there were two patients who presented with ischaemic stroke. Intracranial haemorrhage is a rare, but serious disorder that accounts for approximately $1 \%$ of ICU admissions and carries a mortality of $40 \%$ to $70 \%$. Common causes include hypertensive intracerebral haemorrhage, ruptured berry aneurysm, arteriovenous malformation, eclampsia, anticoagulant toxicity, bleeding disorders and (rarely) bleeding into a brain tumour or cocaine use. The relative risk of intracerebral haemorrhage during pregnancy and the 6 weeks after pregnancy was 5.6 times that for non-pregnant patients. The relative risk of bleeding during pregnancy was 2.5 (95\% confidence interval, 1.0 - 6.4) and increased to 18.2 (95\% confidence interval, $8.7-38.1)$ in the immediate postpartum period. 15 Subarachnoid haemorrhage occurs in one to two per 10,000 pregnancies. There is a three-fold increased risk of subarachnoid haemorrhage during pregnancy and $85 \%$ of subarachnoid haemorrhages occur in the second or third trimester. ${ }^{19,20}$

The risk of bleeding continues into the puerperal period. Theoretical explanations for the increased risk of haemorrhage during pregnancy include an increase in blood volume, stroke volume and cardiac output. Hormone-induced vasodilatation and changes in the vessel wall structure have also been suggested as contributory mechanisms. ${ }^{15}$ Straining during labour would seem to make this a particularly high risk period, but surprisingly only few aneurysms bleed during labour. 15

Cerebral venous thrombosis traditionally has been associated with pregnancy and it accounted for $12 \%$ of all cases in a series of 624 patients in a large International cohort. There may be some geographic differences in the incidence of cerebral venous thrombosis. In a series of 49 Taiwanese patients with stroke during pregnancy, Jeng et al ${ }^{12}$ found that $11(22 \%)$ had cerebral venous sinus thrombosis. In contrast, there was only one case of cerebral venous sinus thrombosis in a series of 31 patients with pregnancy-related stroke reported by Kittner et al from the United States. ${ }^{15}$ In a series of 754 obstetric patients admitted to the ICU of the King Edward Memorial Hospital in Mumbai, India, over a 10year period, 26 admissions (3.5\%) were for cerebral venous sinus thrombosis. ${ }^{21}$ Table 7 shows incidence of cerebral sinus thrombosis in various studies. There is $120 \%$ to $300 \%$ increase in circulating levels of clotting factors during pregnancy. Levels of factor II, VII and X are also increased. The level of protein $S$ is decreased, but that of protein $C$ remains unchanged. These changes along with an inhibited fibrinolytic system result in a marked increase in fibrin generation during pregnancy and puerperium. This hypercoagulable state along with conditions resulting in dehydration during labour and puerperium may be responsible for thrombotic complications in pregnancy 
including cerebral venous thrombosis. Risk factors associated with pregnancy-related cerebral venous sinus thrombosis are maternal age, hyperemesis, delivery by caesarean section, intercurrent infection and maternal hypertension. In a recent report, Jeng et al ${ }^{12}$ noted that $64 \%$ of their 11 patients with pregnancy associated cerebral venous thrombosis were in a hypercoagulable state: four had protein $\mathrm{S}$ deficiency, one had protein $\mathrm{C}$ deficiency and one each had systemic lupus erythematosus and antiphospholipid syndrome. Only a small proportion of patients develop cerebral venous sinus thrombosis during pregnancy, and $66 \%$ to $80 \%$ of cases occur during puerperium. Headache is the commonest symptom of cerebral venous thrombosis and occurs in $95 \%$ of patients. Other manifestations include focal seizures (47\%), paresis (43\%), papilloedema (41\%), altered consciousness (39\%), and isolated intracranial hypertension $(20 \%)$. The diagnosis is made by CT or MR Venogram.

\begin{tabular}{|c|c|}
\hline Study & $\%$ of CSVT \\
\hline Feske et al ${ }^{10}$ & 39 \\
\hline Laing et al11 & 27 \\
\hline Jeng et $\mathrm{al}^{12}$ & 22 \\
\hline Jaigobein et al ${ }^{13}$ & 40 \\
\hline Witllin et al14 & 64 \\
\hline Kittner et al ${ }^{15}$ & 6 \\
\hline Present Study & 25 \\
\hline \multicolumn{2}{|c|}{ Table 7. Distribution of CSVT in Various Studies } \\
\hline
\end{tabular}

Posterior Reversible Encephalopathy Syndrome (PRES) is a constellation of neurological signs and symptoms associated with Magnetic Resonance Imaging (MRI) findings of hyperintensity and oedema on T2 weighted images, mainly in the occipital parietal lobes. While PRES has been seen with a variety of clinical conditions such as eclampsia, hypertensive encephalopathy, immunosuppression and liver failure. The clinical presentation and imaging findings appear to be similar regardless of the underlying disease.

The obstetric literature on PRES has been limited to cases/ case series with the largest patient series $(n=46)$ describing the relationship between eclampsia and PRES. Brewer and colleagues ${ }^{22}$ reported that among patients with PRES, headache was the most common symptom (87.2\%) followed by altered mental status $(51.1 \%)$ and visual disturbances (34\%). In a study by Nelli Fisher et al, ${ }^{23}$ while a headache was present in all preeclamptic patients with PRES. In the present study, there were thirteen patients that were diagnosed with PRES. All of them presented with features of preeclampsia. All patients had headache and elevated blood pressures at the time of admission. Ten patients had seizures. Visual symptoms were present in nine cases and six patients presented with altered sensorium. Imaging showed presence of oedema in occipital regions.

Gliomas are the commonest tumours in pregnant patients and account for $38 \%$ of all primary brain tumours followed by meningiomas (28\%) and acoustic neuromas (14\%). Most brain tumours expand considerably during pregnancy and often manifest for the first time in pregnant patients. Peritumoral oedema can worsen as a result of a generalised increase in intracellular and extracellular fluid compartments in the late second and third trimesters. ${ }^{24}$ Headache, vomiting, visual symptoms, focal neurologic deficits and seizures are common symptoms of primary brain tumours.

In our study three patients had tumours. One patient presented with facial nerve palsy in the postpartum period. Imaging was suggestive of glioma. Patient was successfully operated and her post-operative recovery was uneventful. Second case was glioblastoma, diagnosed during 2nd trimester and she presented with headache, vomiting and altered sensorium.

Third case was diagnosed as cutaneous neurofibromatosis. She had multiple neurofibromas all over the body which appeared in first pregnancy and the size, number of lesions increased in second pregnancy. There is a possible role of oestrogens in the appearance and growth of neurofibroma in pregnancy.

The most common movement disorders encountered in pregnancy include Restless Legs Syndrome (RLS), Chorea Gravidarum (CG), Parkinson's Disease (PD), Essential Tremor (ET) and Huntington's Disease (HD). Chorea gravidarum is a generic term for chorea of any cause starting during pregnancy. CG begins after the first trimester in half of patients, spontaneously abates in approximately one-third before delivery and resolves as the pregnancy progresses and may recur in 1 in 5 women in subsequent pregnancies. ${ }^{25}$ Maternal and foetal risks are not elevated.

\begin{tabular}{|c|c|c|c|}
\hline Condition & Sarella et al8 $^{8}$ & Shubha et al6 $^{6}$ & $\begin{array}{c}\text { Present } \\
\text { Study }\end{array}$ \\
\hline $\begin{array}{c}\text { Movement } \\
\text { disorder }\end{array}$ & $2(3.64 \%)$ & $2(3.8 \%)$ & $3(4.4 \%)$ \\
\hline \multicolumn{4}{|c|}{ Table 8. Movement Disorders during Pregnancy and } \\
Puerperium
\end{tabular}

In the present study, 3 cases presented with chorea. Two patients were diagnosed with chorea gravidarum. Another case was diagnosed as Wilson's disease. Our study findings are similar to other studies as shown in Table 8.

An increase in the incidence of idiopathic facial palsy during pregnancy and postpartum period was found in previous studies. ${ }^{26}$ Prognosis is excellent and similar to that observed in non-pregnant patients. Sarella et al ${ }^{8}$ reported one case of facial nerve palsy during third trimester of pregnancy. Raymond L Hilsinger, Jr. and Kedar Karim et al27 reported 42 cases of Bell's palsy during pregnancy. Of the 42 cases in pregnancy 31 occurred in the third trimester, five in the first two weeks postpartum and six in the first two trimesters. In our study, three patients presented with facial nerve palsy. One patient presented during the postpartum period and had bilateral facial nerve palsy, whose CSF and imaging findings were normal. Two cases presented in second trimester had unilateral LMN facial palsy. All the three patients recovered completely. Guillain-Barre syndrome affects $6-24 / 100,000$ of population during pregnancy.

Incidence in pregnancy is not greater than expected in non-pregnant women of child bearing age. ${ }^{28} \mathrm{~GB}$ syndrome is known to worsen during the postpartum period due to increase in delayed hypersensitivity relapses during subsequent pregnancies can occur. Pregnancy, labour and delivery proceed normally for most women. Both plasmapheresis and immunoglobulins were used with good maternal and foetal outcome. In our study, three patients were diagnosed with GBS. All had AIDP, one case presented 
during second trimester and two cases during postpartum period. All three patients improved spontaneously.

\section{CONCLUSION}

Many different neurological conditions may be encountered during pregnancy. Epilepsy and cerebrovascular disorders emerge as the predominant neurological disorders during pregnancy and puerperium. Effects of these conditions on pregnancy and the effects of pregnancy on the course of these disorders should be kept in mind when dealing with these conditions in pregnancy.

\section{REFERENCES}

[1] To WK, Cheung RT. Neurological disorders in pregnancy. Hong Kong Med J 1997;3(4):400-8.

[2] Gupta S, Rohatgi A, Sharma SK, et al. A Study of neurological disorders during pregnancy and puerperium. Annals of Indian Academy of neurology 2006;9(3):152-7.

[3] Janaki S, Thomas L. Neurological complications in pregnancy and puerperium. Neurol India 1963;11:128-37.

[4] Srinivasan SK, Ramamurthy B. Neurological disorders during pregnancy and puerperium. J Assoc Phys India 1971;19:705-13.

[5] Agarwal K. Neurological disorders in pregnancy and puerperium. J Assoc Phys India 1968;19:705-13.

[6] Shubha L, Rao SV, Raghavendra S. Neurological disorders in pregnancy and puerperium. IOSR Journal of Dental and Medical Sciences 2017;16(4):80-5.

[7] Knight AH, Rhing EG. Epilepsy and pregnancy: a study of 153 pregnancies in 59 patients. Epilepsia 1975;16(1):99-110.

[8] Sarella LK, Rao DS. Neurological disorders in pregnancy and puerperium, Rangaraya Medical College, Kakinada. Sri Lanka Journal of Obstetrics and Gynaecology 2014;36(3):74-8.

[9] Schmidt D, Canger R, Avanzini G, et al. Change in seizure frequency in pregnant epileptic women. J Neurol Neurosurg Psychiatry 1983;46(8):751-5.

[10] Feske SK, Klein AM, Ferrante KL. Clinical risk factors predict pregnancy-associated strokes. Poster presented at: International Stroke Conference, February 18-19, San Diego, CA, 2009.

[11] Liang CC, Chang SD, Lai SL, et al. Stroke complicating pregnancy and the puerperium. Eur J Neurol 2006;13(11):1256-60.

[12] Jeng JS, Tang SC, Yip PK. Incidence and etiologies of stroke during pregnancy and puerperium as evidenced in Taiwanese women. Cerebrovasc Dis 2004;18(4):290-5.

[13] Jaigobin C, Silver FL. Stroke and pregnancy. Stroke 2000;31(12):2948-51.
[14] Witlin AG, Friedman SA, Egerman RS, et al. Cerebrovascular disorders complicating pregnancy beyond eclampsia. Am J Obstet Gynecol 1997;176(6):1139-45.

[15] Kittner SJ, Stern BJ, Feeser BR, et al. Pregnancy and the risk of stroke. N Engl J Med 1996;335(11):768-74.

[16] Sharshar T, Lamy C, Mas JL. Incidence and causes of stroke associated with pregnancy and puerperium. A study in public hospitals of Ile de France. Stroke in Pregnancy Study Group. Stroke 1995;26(6):930-6.

[17] Awada A, al Rajeh S, Duarte R, et al. Stroke and pregnancy. Int J Gynaecol Obstet 1995;48(2):157-61.

[18] Singhal AB, Hajj-Ali RA, Topcuoglu MA, et al. Reversible cerebral vasoconstriction syndromes: analysis of 139 cases. Arch Neurol 2011;68(8):100512.

[19] Carhuapoma JR, Tomlinson MW, Levine SR. Neurologic diseases. In: James DK, Steer PJ, Weiner CP, et al. eds. High risk pregnancy: management options. $2^{\text {nd }}$ edn. London: WB Saunders 1999: p. 803-36.

[20] Shehata HA, Okosun H. Neurological disorders in pregnancy. Curr Opin Obstet Gynecol 2004;16(2):11722.

[21] Munnur U, Karnad DR, Bandi VD, et al. Critically ill obstetric patients in an American and an Indian public hospital: comparison of case-mix, organ dysfunction, intensive care requirements and outcomes. Intensive Care Med 2005;31(8):1087-94.

[22] Brewer J, Owens MY, Wallace K, et al. Posterior reversible encephalopathy syndrome in 46 of 47 patients with eclampsia. Am J Obstet Gynecol 2013;208(6):468.e1-6.

[23] Fisher N, Saraf S, Egbert N, et al. Clinical correlates of posterior reversible encephalopathy syndrome in pregnancy presented at the annual clinical meetings ACM meeting in Chicago in May 2014. Obstetrics and Gynecology 2014;123(Suppl 1):169S.

[24] Stevenson CB, Thompson RC. The clinical management of intracranial neoplasms in pregnancy. Clin Obstet Gynecol 2005;48(1):24-37.

[25] Lawrence I, Golbe P. Pregnancy and movement disorders. Ed Lesley Kramer Day. Neurologic Clinics 1994;12(3):497-507.

[26] Hilsinger Jr RL, Adour KK, Doty HE. Idiopathic facial paralysis, pregnancy and menstrual cycle. Ann Otol Rhinol 1975;84(4 Pt 1):433-42.

[27] Hilsinger RL, Anour KK, Doty HE. Idiopathic facial paralysis, pregnancy, and the menstrual cycle, Presented at the meeting of the American Otological Society, Inc., Atlanta Georgia, April 11-12, 1975.

[28] Goyal V, Misra BK, Singh S, et al. Acute inflammatory demyelinating polyneuropathy in patients with pregnancy. Neurol India 2004;52(2):283-4. 